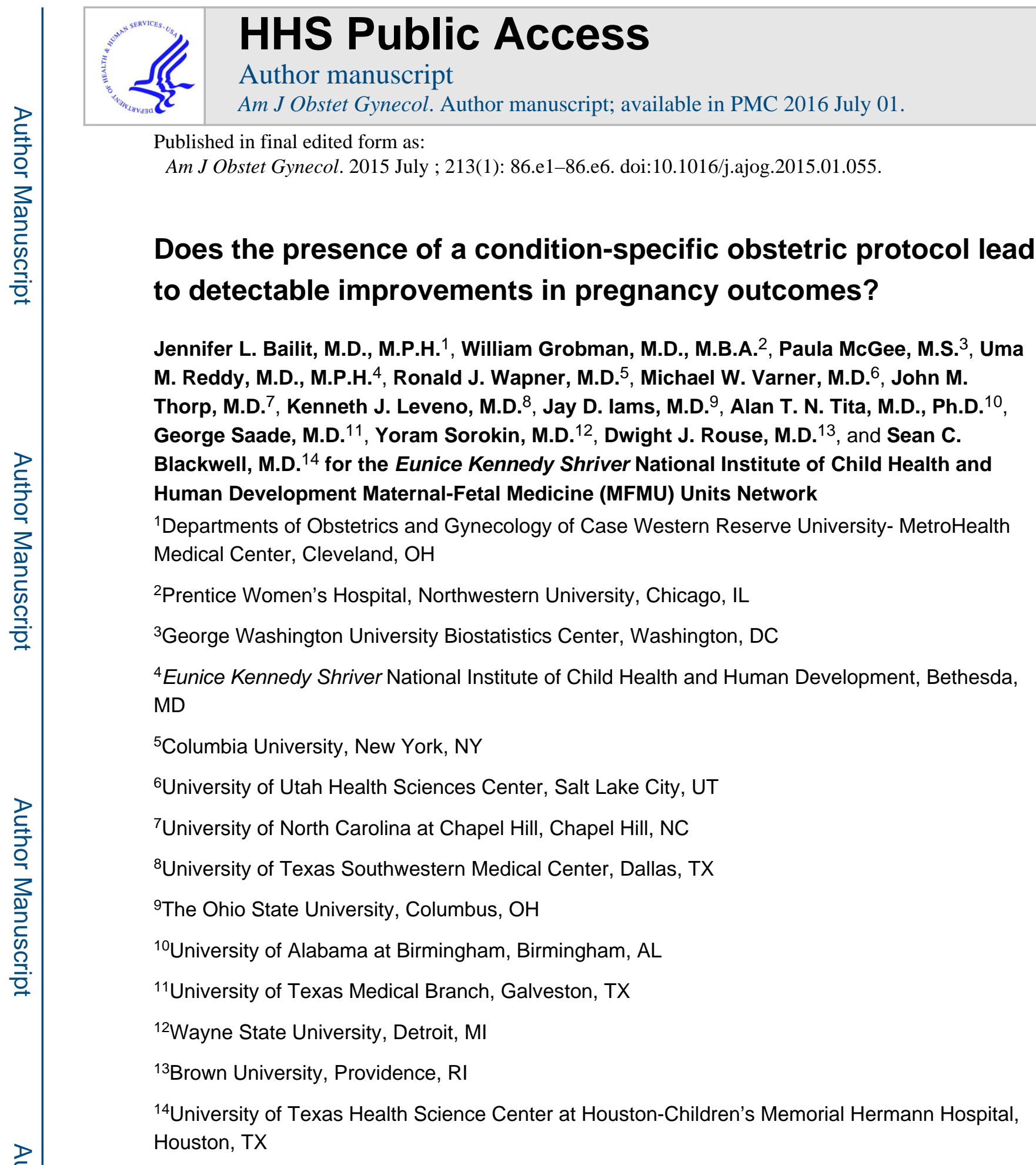

Published in final edited form as:

Am J Obstet Gynecol. 2015 July ; 213(1): 86.e1-86.e6. doi:10.1016/j.ajog.2015.01.055.

\title{
Does the presence of a condition-specific obstetric protocol lead to detectable improvements in pregnancy outcomes?
}

Jennifer L. Bailit, M.D., M.P.H. ${ }^{1}$, William Grobman, M.D., M.B.A. ${ }^{2}$, Paula McGee, M.S. ${ }^{3}$, Uma M. Reddy, M.D., M.P.H. ${ }^{4}$, Ronald J. Wapner, M.D. ${ }^{5}$, Michael W. Varner, M.D. ${ }^{6}$, John M.

Thorp, M.D. ${ }^{7}$, Kenneth J. Leveno, M.D. ${ }^{8}$, Jay D. lams, M.D. ${ }^{9}$, Alan T. N. Tita, M.D., Ph.D. ${ }^{10}$, George Saade, M.D. ${ }^{11}$, Yoram Sorokin, M.D. ${ }^{12}$, Dwight J. Rouse, M.D. ${ }^{13}$, and Sean C. Blackwell, M.D. ${ }^{14}$ for the Eunice Kennedy Shriver National Institute of Child Health and Human Development Maternal-Fetal Medicine (MFMU) Units Network

Departments of Obstetrics and Gynecology of Case Western Reserve University- MetroHealth

2Prentice Women's Hospital, Northwestern University, Chicago, IL

${ }^{3}$ George Washington University Biostatistics Center, Washington, DC

${ }^{4}$ Eunice Kennedy Shriver National Institute of Child Health and Human Development, Bethesda, MD

${ }^{5}$ Columbia University, New York, NY

${ }^{6}$ University of Utah Health Sciences Center, Salt Lake City, UT

${ }^{7}$ University of North Carolina at Chapel Hill, Chapel Hill, NC

University of Texas Southwestern Medical Center, Dallas, TX

${ }^{9}$ The Ohio State University, Columbus, $\mathrm{OH}$

10University of Alabama at Birmingham, Birmingham, AL

Corresponding author: Jennifer Bailit, MD, MPH, 2500 MetroHealth Dr, Cleveland, OH 44107, Phone 216-778-3550, Fax 216-778-8847, jbailit@metrohealth.org.

* Other members of the Eunice Kennedy Shriver National Institute of Child Health and Human Development Maternal-Fetal Medicine Units Network are listed in the Appendix

This study was presented at the 32nd Annual meeting of the Society for Maternal-Fetal Medicine in Dallas, TX on February 9, 2012

Publisher's Disclaimer: This is a PDF file of an unedited manuscript that has been accepted for publication. As a service to our customers we are providing this early version of the manuscript. The manuscript will undergo copyediting, typesetting, and review of the resulting proof before it is published in its final citable form. Please note that during the production process errors may be discovered which could affect the content, and all legal disclaimers that apply to the journal pertain. 


\section{Abstract}

Objective-To evaluate whether the presence of condition-specific obstetric protocols within a hospital was associated with better maternal and neonatal outcomes.

Study Design-Cohort study of a random sample of deliveries performed at 25 hospitals over three years. Condition-specific protocols were collected from all hospitals and categorized independently by two authors. Data on maternal and neonatal outcomes, as well as data necessary for risk adjustment were collected. Risk-adjusted outcomes were compared according to whether the patient delivered in a hospital with condition-specific obstetric protocols at the time of delivery.

Results-Hemorrhage-specific protocols were not associated with a lower rate of postpartum hemorrhage or with fewer cases of EBL >1000cc. Similarly, in the presence of a shoulder dystocia protocol, there were no differences in the frequency of shoulder dystocia or number of shoulder dystocia maneuvers used. Conversely, preeclampsia-specific protocols were associated with fewer ICU admissions (OR 0.28, 95\% CI 0.18-0.44) and fewer cases of severe maternal hypertension (OR $0.86,95 \%$ CI $0.77-0.96$ ).

Conclusion-The presence of condition-specific obstetric protocols was not consistently shown to be associated with improved risk-adjusted outcomes. Our study would suggest that the presence or absence of a protocol does not matter and regulations to require protocols are not fruitful.

\section{INTRODUCTION}

The importance of measuring and improving quality in obstetrics has been increasingly recognized as a priority. As a result, an increasing number of studies and opinions concerned with how to measure and improve quality of care in obstetrics have been published. ${ }^{1-8}$ In this literature, the concept of using protocols to improve care has been suggested as an important component of patient safety initiatives. Protocols are a plan of treatment that provide detailed instructions for the medical team on what to do once a specific complication, such as hemorrhage, shoulder dystocia or preeclampsia has arisen. Pressure to adapt protocols may also come from government regulation and from malpractice carriers. ${ }^{9,10}$ These regulations often do not have requirements on how the protocols are implemented, just that a protocols are required. Correspondingly, many departments have started implementing condition-specific protocols.

Despite the increasing emphasis on the use of protocols to improve care, there is relatively little empiric evidence that obstetric outcomes are improved through their use. Also, studies that have demonstrated an improvement have tended to be performed at single centers, and as such the generalizability of the findings is uncertain. ${ }^{8}$ One further difficulty in determining whether protocols are associated with better outcomes is that preexisting patient characteristics also influence patient outcomes, and changes over time in these characteristics need to be accounted for in any longitudinal study. We hypothesized that hospitals with condition-specific obstetric protocols in place would have better risk-adjusted patient outcomes than hospitals without such protocols. 


\section{METHODS}

Between 2008 and 2011, we performed a cohort study at 25 hospitals in the Eunice Kennedy Shriver National Institute of Child Health and Human Development Maternal-Fetal Medicine Units (MFMU) Network. This study, the Assessment of Perinatal EXcellence (APEX), was designed to develop quality measures for intrapartum obstetrical care. The APEX study was approved by the Institutional Review Board at each participating institution under a waiver of informed consent. This is a planned secondary analysis of the APEX data set.

Each hospital that participated in the study submitted all existing labor and delivery protocols each quarter that the study was ongoing. Research staff at participating hospitals was instructed to submit all potential protocols pertaining to obstetrics and to provide the dates that the individual protocols went into (or out of) effect. Two authors (JB and WAG) then independently reviewed the protocols and determined whether the submissions were truly condition-specific protocols (e.g., as opposed, for example, to instructions narrowly directed toward single medication administration) and what specific topics they pertained to (i.e., hemorrhage, preeclampsia, or shoulder dystocia). Protocols had to involve regulation of provider behavior as well as other hospital systems issues in order to be considered a protocol. The two reviewers determined whether a condition-specific protocol was present or absent for the particular center. The content and quality of the protocol as well as the steps taken to implement the protocol were not assessed. Disagreements were resolved by conversation between the two reviewers until consensus was reached.

Patients were then categorized by whether they delivered in an institution at a time when specific protocols were in effect. For example, if a hemorrhage and shoulder dystocia protocol went into effect at a given hospital in February, patients delivering in January of that year were categorized as not having delivered in the presence of a protocol, but patients from February on were categorized as having delivered in the presence of both of these protocols.

Methods for risk adjustment of patient characteristics, and the specific risk-adjustment characteristics for hemorrhage, have been described previously. ${ }^{11}$ The same methodologies were used to determine the patient characteristics that should be used for risk adjustment for preeclampsia and shoulder dystocia. Only women eligible for a given outcome were included (e.g., women who did not deliver vaginally were not assessed with regard to shoulder dystocia). Variables used in the risk adjustment models are shown in Table 2.

Analysis was performed to determine whether risk-adjusted outcomes relevant to each complication were associated with the presence of relevant protocols at the time of delivery. For example, we assessed whether the presence of a postpartum hemorrhage protocol was associated with less frequent postpartum hemorrhages (i.e., estimated blood loss $>1000 \mathrm{cc}$ ) or the severity of the hemorrhage (severe hemorrhage was defined as either an estimated blood loss $21500 \mathrm{cc}$ at delivery, a blood transfusion, or a hysterectomy performed for hemorrhage, placenta accreta or uterine atony). The analysis of the hemorrhage outcomes excluded women whose reason for admission was bleeding or abruption, given the greater 
potential that their outcomes were related to events prior to admission. Only women whose hemorrhage started in the hospital were eligible so that hospitals were not held accountable for the severity of a hemorrhage when much of the blood loss was beyond their control before admission. For women who had been given the diagnosis of preeclampsia, we evaluated whether the presence of preeclampsia-specific protocols were associated with any of the following markers of severity: eclampsia, any persistent severe blood pressures defined as two maternal systolic blood pressures $\geq 160 \mathrm{mmHg}$ or any two diastolic blood pressures $\geq 110 \mathrm{mmHg}$, admission to ICU, pulmonary edema, creatinine $>2.0 \mathrm{mg} / \mathrm{dl}$ (if no creatinine value was present in the medical record, we assumed it did not exceed this value). Shoulder dystocia protocols were assessed to determine whether their presence was associated with the frequency of shoulder dystocia or the severity of the shoulder dystocia as assessed by the number of maneuvers ( $\mathcal{2}$ and 23 ) used to relieve shoulder dystocia. While ideally we would track poor infant outcomes for shoulder dystocia, we were unable to examine brachial plexus injury, cord blood gases, or bones fractures due to low numbers of outcomes.

Univariable comparisons were performed with Chi square tests. Hierarchal models were developed for the outcomes of hemorrhage and shoulder dystocia and logistic models for the preeclampsia outcomes, with adjustment for patient characteristics, to estimate the independent association between the presence of a condition-specific protocol and obstetric complications. Logistical models were used for the eclampsia outcomes because the low number of outcomes did not allow for use of a hierarchal technique. No imputation for missing data was performed. Hierarchal models take into account hospital of delivery and hospital was added to the logistics model for eclampsia.

\section{RESULTS}

Data were collected from 115,502 women. Unadjusted outcome rates are shown in Table 1. The frequencies of hemorrhage outcomes and ICU admission for preeclampsia were significantly different between hospitals with and without protocols in place. Hospitals with a hemorrhage protocols had higher rates of hemorrhage and hospitals that did not have a preeclampsia protocol in place had higher rates of ICU admissions.

Variables included in the final risk adjustment models are shown in Table 2 and the results of the multivariable models used to estimate the association between the presence of a protocol and risk-adjusted outcomes are shown in Table 3. The presence of a hemorrhage specific protocol was not associated with any difference in odds of hemorrhage (EBL $>1000 \mathrm{cc}$ ) occurring or the severity of the post partum hemorrhage in the risk adjusted model. Similarly, there were no differences in the odds of a shoulder dystocia occurring or the severity of the shoulder dystocia as in hospitals with shoulder dystocia protocols. Conversely, preeclampsia-specific protocols were associated with improved maternal outcomes as measured by lower rates of ICU admission or persistent severe maternal hypertension. Preeclampsia protocols were not, however, associated with other markers of severity such as eclampsia, pulmonary edema, or creatinine $\geq 2.0 \mathrm{mg} / \mathrm{dl}$. 


\section{Discussion}

In these analyses, we did not find a consistent relationship between the presence of condition-specific protocols and the severity of obstetrics complications. The presence of hemorrhage or shoulder dystocia protocols did not appear to affect the frequency of the outcome itself or the severity of related adverse outcomes. Conversely, the presence of a preeclampsia protocol was associated with less hypertensive morbidity by some measures.

It is important to recognize the importance of risk adjusting for patient factors in this analysis. For example, when unadjusted rates of hemorrhage are compared between hospitals with and without hemorrhage protocols, there appears to be a significant difference (Table 2). However, when patient risk factors are taken into account, these differences are no longer present.

We did find that preeclampsia protocols were associated with lower rates of persistent severe maternal hypertension and ICU admissions, but not other adverse outcomes related to preeclampsia. It is possible that eclampsia, pulmonary edema, and an elevated creatinine are sufficiently rare (with correspondingly wide confidence intervals) that this study does not have adequate power to detect differences in these outcomes and meaningful conclusions cannot be reached. The same possibility exists for adverse outcomes associated with shoulder dystocia.

One explanation for the finding that preeclampsia protocols changed some outcomes but that shoulder dystocia and hemorrhage protocols did not is that preeclampsia occurs more frequently in hospitals and thus providers may have better familiarity and adherence to the protocol. We do not have any information within this data set to be able to explore this hypothesis more fully.

The findings of this analysis stand in contrast to results of some prior studies. For example, Grobman et al. did show an improvement in outcomes after the introduction of a shoulder dystocia protocol at their institution. ${ }^{8}$ However, introduction of the protocol incorporated team simulation. Data from Pogorzelska et al. also suggest that the mere presence of a protocol, without other supporting systems in place, does not inevitably lead to improved outcomes. They surveyed ICUs to see whether they had implemented a policy to prevent ventilator-associated pneumonia, whether they monitored the adherence to this policy, and the adherence rate.. They found that a policy that was not actively monitored and that did not have compliance rates of $95 \%$ or greater, did not result in any effect on outcomes. ${ }^{12}$ Similarly, Urbach et al. found that the implementation of surgical check lists in Ontario Hospitals did not improve patient outcomes. They speculated that while intensive team training or monitoring of compliance could have potentially made the checklists more effective, as implemented, no improvement in outcomes was seen. ${ }^{13}$

Further evidence that it is not the protocol itself that makes a difference but that it is the protocol in combination with the method of implementation is found in a study by Clark et al. ${ }^{3}$ Researching how to decrease the rate of non-medically indicated scheduled deliveries $<39$ weeks, they studied the frequency of adherence to a new policy against such deliveries after three different implementation approaches: (1) education alone with no active 
surveillance; (2) no barrier to scheduling non-medically indicated deliveries but peer review after one had occurred; or (3) the presence of a "hard stop" that prevented practitioners from scheduling a delivery that did not meet the policy. Despite a new protocol being present in all scenarios, a "hard stop" resulted in a significantly larger reduction in non-medically indicated deliveries.

In our study, we simply assessed whether a protocol was present or not present and showed that the presence of a protocol had little association with the presence or severity of poor outcomes. We were not able to assess the quality of the protocol nor quantify or categorize the different implementation approaches. Thus, we cannot comment whether particular protocols or implementation methods were associated with improved outcomes. In an effort to regulate and improve quality, some insurance companies request that hospitals have a protocol in place. Our study would suggest that the presence or absence of a protocol does not matter and regulation attempts along this line are not fruitful. Further research seeking to understand the elements of a high quality protocol or the best implementation techniques to use are necessary to ensure that the presence of protocols translates into improved outcomes. Merely requiring that a hospital have a protocol is not enough to affect outcomes.

\section{Acknowledgments}

The project described was supported by grants from the Eunice Kennedy Shriver National Institute of Child Health and Human Development (NICHD) [HD21410, HD27869, HD27915, HD27917, HD34116, HD34208, HD36801, HD40500, HD40512, HD40544, HD40545, HD40560, HD40485, HD53097, HD53118] and the National Center for Research Resources [UL1 RR024989; 5UL1 RR025764]. Comments and views of the authors do not necessarily represent views of the NICHD.

This study was sponsored by the Eunice Kennedy Shriver National Institute of Child Health and Human Development (NICHD) Maternal-Fetal Medicine Units (MFMU) Network.

The authors thank the following subcommittee members who participated in protocol development and coordination between clinical research centers (Cynthia Milluzzi, R.N. and Joan Moss, R.N.C., M.S.N.), protocol/ data management and statistical analysis (Madeline M. Rice, Ph.D. and Elizabeth Thom, Ph.D.), and protocol development and oversight (Brian M. Mercer, M.D. and Catherine Y. Spong, M.D.)

\section{References}

1. Bailit JL. Measuring the quality of inpatient obstetrical care. Obstetrical \& Gynecological Survey. 2007; 62:207-13. [PubMed: 17306043]

2. Clark SL, Belfort MA, Byrum SL, et al. Improved outcomes, fewer cesarean deliveries, and reduced litigation: results of a new paradigm in patient safety. American Journal of Obstetrics \& Gynecology. 2008; 199:105.e1-7. [PubMed: 18468573]

3. Clark SL, Frye DR, Meyers JA, et al. Reduction in elective delivery at $<39$ weeks of gestation: comparative effectiveness of 3 approaches to change and the impact on neonatal intensive care admission and stillbirth. American Journal of Obstetrics \& Gynecology. 2010; 203:449.e1-6. [PubMed: 20619388]

4. Oshiro BT, Henry E, Wilson J, et al. Decreasing Elective Deliveries Before 39 Weeks of Gestation in an Integrated Health Care System. Obstetrics \& Gynecology. 2009; 113:804-11. [PubMed: 19305323]

5. The Ohio Perinatal Quality Collaborative Writing Committee. A statewide initiative to reduce inappropriate scheduled births at 36 0/7 to 38 6/7 weeks' gestation. American Journal of Obstetrics and Gynecology. 2010; 202:243.e1-43.e8. [PubMed: 20207241]

6. Ohio Level II newborn care services specific requirements.3701-84-54, 2008. 
7. Pettker CM, Thung SF, Norwitz ER, et al. Impact of a comprehensive patient safety strategy on obstetric adverse events. Am J Obstet Gynecol. 2009; 200:492.e1-92.e8. [PubMed: 19249729]

8. Grobman WA, Miller D, Burke C, Hornbogen A, Tam K, Costello R. Outcomes associated with introduction of a shoulder dystocia protocol. American Journal of Obstetrics and Gynecology. 2011; 205:513-17. [PubMed: 21703592]

9. Ohio Maternity unit patient care standards 3701-7-08, 2012.

10. Wilson, L. An evidence-based approach is born. Hospitals, physicians use protocols to cut costs from avoidable OB/GYN injuries. Modern Health care: Crain Communications. Dec 20. 2010

11. Bailit JL, Grobman WA, Rice MM, et al. Risk-adjusted models for adverse obstetric outcomes and variation in risk-adjusted outcomes across hospitals. American Journal of Obstetrics and Gynecology. 2013; 209:446.e1-46.e30. [PubMed: 23891630]

12. Pogorzelska M, Stone PW, Furuya EY, et al. Impact of the ventilator bundle on ventilatorassociated pneumonia in intensive care unit. Int J Qual Health Care. 2011; 23:538-44. [PubMed: 21821603]

13. Urbach DR, Govindarajan A, Saskin R, Wilton AS, Baxter NN. Introduction of Surgical Safety Checklists in Ontario, Canada. New England Journal of Medicine. 2014; 370:1029-38. [PubMed: 24620866]

\section{Appendix}

In addition to the authors, other members of the Eunice Kennedy Shriver National Institute of Child Health and Human Development Maternal-Fetal Medicine Units Network are as follows:

Case Western Reserve University-MetroHealth Medical Center, Cleveland, $\mathrm{OH}$ - B. Mercer, C. Milluzzi, W. Dalton, T. Dotson, P. McDonald, C. Brezine, A. McGrail

Northwestern University, Chicago, IL - G. Mallett, M. Ramos-Brinson, A. Roy, L. Stein, P. Campbell, C. Collins, N. Jackson, M. Dinsmoor (NorthShore University HealthSystem), J. Senka (NorthShore University HealthSystem), K. Paychek (NorthShore University HealthSystem), A. Peaceman

Columbia University, New York, NY - M. Talucci, M. Zylfijaj, Z. Reid (Drexel U.), R. Leed (Drexel U.), J. Benson (Christiana H.), S. Forester (Christiana H.), C. Kitto (Christiana H.), S. Davis (St. Peter's UH.), M. Falk (St. Peter's UH.), C. Perez (St. Peter's UH.)

University of Utah Health Sciences Center, Salt Lake City, UT - K. Hill, A. Sowles, J. Postma (LDS Hospital), S. Alexander (LDS Hospital), G. Andersen (LDS Hospital), V. Scott (McKay-Dee), V. Morby (McKay-Dee), K. Jolley (UVRMC), J. Miller (UVRMC), B. Berg (UVRMC)

University of North Carolina at Chapel Hill, Chapel Hill, NC - K. Dorman, J. Mitchell, E. Kaluta, K. Clark (WakeMed), K. Spicer (WakeMed), S. Timlin (Rex), K. Wilson (Rex)

University of Texas Southwestern Medical Center, Dallas, TX - L. Moseley, M. Santillan, J. Price, K. Buentipo, V. Bludau, T. Thomas, L. Fay, C. Melton, J. Kingsbery, R. Benezue University of Pittsburgh, Pittsburgh, PA - S. Caritis, H. Simhan, M. Bickus, D. Fischer, T. Kamon (deceased), D. DeAngelis 
The Ohio State University, Columbus, $\mathrm{OH}$ - P. Shubert (St. Ann's), C. Latimer, L. Guzzo (St. Ann's), F. Johnson, L. Gerwig (St. Ann's), S. Fyffe, D. Loux (St. Ann's), S. Frantz, D. Cline, S. Wylie, J. Iams

University of Alabama at Birmingham, Birmingham, $A L$ - M. Wallace, A. Northen, J. Grant, C. Colquitt

University of Texas Medical Branch, Galveston, TX - J. Moss, A. Salazar, A. Acosta, G. Hankins

Wayne State University, Detroit, MI - N. Hauff, L. Palmer, P. Lockhart, D. Driscoll, L. Wynn, C. Sudz, D. Dengate, C. Girard, S. Field

Brown University, Providence, RI - P. Breault, F. Smith, N. Annunziata, D. Allard, J. Silva, M. Gamage, J. Hunt, J. Tillinghast, N. Corcoran, M. Jimenez

The University of Texas Health Science Center at Houston-Children's Memorial Hermann Hospital, Houston, TX - F. Ortiz, P. Givens, B. Rech, C. Moran, M. Hutchinson, Z. Spears, C. Carreno, B. Heaps, G. Zamora

Oregon Health \& Science University, Portland, OR - J. Tolosa, J. Seguin, M. Rincon, J. Snyder, C. Farrar, E. Lairson, C. Bonino, W. Smith (Kaiser Permanente), K. Beach (Kaiser Permanente), S. Van Dyke (Kaiser Permanente), S. Butcher (Kaiser Permanente)

The George Washington University Biostatistics Center - E. Thom, M. Rice, Y. Zhao, P. McGee, V. Momirova, R. Palugod, B. Reamer, M. Larsen, T. Williams

Eunice Kennedy Shriver National Institute of Child Health and Human Development, Bethesda, $M D-C$. Spong, S. Tolivaisa

MFMU Network Steering Committee Chair (Medical University of South Carolina, Charleston, SC) - J. P. Van Dorsten, M.D. 


\section{Table 1}

Unadjusted outcomes by protocol status

\begin{tabular}{|c|c|c|c|}
\hline \multicolumn{4}{|c|}{ Descriptive table of outcomes by protocol status } \\
\hline & $\begin{array}{c}\text { Hospital did not have a } \\
\text { hemorrhage protocol at time of } \\
\text { delivery }(\mathrm{N}=85,291)\end{array}$ & $\begin{array}{l}\text { Hospital did have a hemorrhage } \\
\text { protocol at time of delivery } \\
\qquad(\mathrm{N}=\mathbf{2 6 , 2 3 6 )}\end{array}$ & $\begin{array}{l}\text { P-value comparing } \\
\text { these groups }\end{array}$ \\
\hline $\mathrm{EBL}>1000 \mathrm{cc}$ & $7,381(8.7 \%)$ & $4,240(16.2 \%)$ & $<0.01$ \\
\hline \multirow[t]{2}{*}{ Severe PPH } & $1,772(2.1 \%)$ & $679(2.6 \%)$ & $<0.01$ \\
\hline & $\begin{array}{l}\text { Hospital did not have a dystocia } \\
\text { protocol at time of delivery } \\
\qquad(\mathrm{N}=59,852)\end{array}$ & $\begin{array}{l}\text { Hospital did have a dystocia } \\
\text { protocol at time of delivery } \\
\qquad(\mathrm{N}=18,503)\end{array}$ & $\begin{array}{c}\text { P-value comparing these } \\
\text { groups }\end{array}$ \\
\hline Shoulder dystocia & $1,641(2.7 \%)$ & $469(2.5 \%)$ & 0.13 \\
\hline \multirow[t]{2}{*}{ Number of maneuvers $\geq 3$} & $285(0.5 \%)$ & $117(0.6 \%)$ & 0.02 \\
\hline & $\begin{array}{l}\text { Hospital did not have a preeclampsia } \\
\text { protocol at time of delivery } \\
\qquad(\mathrm{N}=9,598)\end{array}$ & $\begin{array}{l}\text { Hospital did have a preeclampsia } \\
\text { protocol at time of delivery } \\
\qquad(\mathrm{N}=1,931)\end{array}$ & $\begin{array}{c}\text { P-value comparing these } \\
\text { groups }\end{array}$ \\
\hline Eclampsia & $32(0.3 \%)$ & $10(0.5 \%)$ & 0.22 \\
\hline Severe Hypertension ${ }^{*}$ & $4,345(45 \%)$ & $800(41 \%)$ & 0.002 \\
\hline Admission to ICU & $373(3.9 \%)$ & $22(1.1 \%)$ & $<0.0001$ \\
\hline Pulmonary edema & $104(1.1 \%)$ & $19(0.98 \%)$ & 0.81 \\
\hline $\begin{array}{l}\text { Creatinine } \geq 2 \mathrm{mg} / \mathrm{dL} \text { (if missing } \\
\text { assume }<2 \text { ) }\end{array}$ & $80(0.83 \%)$ & $18(0.93 \%)$ & 0.69 \\
\hline
\end{tabular}

* Any two maternal SBP $\geq 160 \mathrm{mmHg}$ or any two maternal DBP $\geq 110 \mathrm{mmHg}$

$\mathrm{N}=$ number of women delivering in hospitals during period with or without a specific protocol 
Table 2

Patient risk adjustors by condition type

\begin{tabular}{|c|c|c|c|}
\hline & Postpartum Hemorrhage & Shoulder dystocia & Preeclampsia \\
\hline Denominator size for each outcome (with all non-missing covariates) & 105,165 & 75,910 & 11,529 \\
\hline \multicolumn{4}{|l|}{ Maternal characteristics } \\
\hline Age & - & & - \\
\hline Body mass index at delivery & & - & $\bullet$ \\
\hline \multicolumn{4}{|l|}{ Cigarette use during pregnancy } \\
\hline \multicolumn{4}{|l|}{ Cocaine or methamphetamine use during pregnancy } \\
\hline Insurance status & - & - & • \\
\hline More than two prenatal care visits & - & & \\
\hline Obstetric history & - & - & \\
\hline Any hypertension & • & & \\
\hline Diabetes mellitus & - & $\bullet$ & \\
\hline Anticoagulant use during pregnancy & $\bullet$ & & \\
\hline Multiple gestation & • & & \\
\hline Placenta previa & $\bullet$ & & \\
\hline Placenta accreta & $\bullet$ & & \\
\hline Placental abruption & - & & \\
\hline \multicolumn{4}{|l|}{ PROM/PPROM } \\
\hline \multicolumn{4}{|l|}{ GBS status } \\
\hline Type of Labor & & - & \\
\hline Gestational Age & & $\bullet$ & 0 \\
\hline
\end{tabular}


Table 3

Risk-Adjusted outcomes by protocol status

\begin{tabular}{|l|c|l|l|l|}
\hline & $\begin{array}{c}\text { Outcome Odds ratios associated with having a protocol } \\
\text { for the specified complication }\end{array}$ & Lower CI & Upper CI & P \\
\hline Hemorrhage outcomes & & & & \\
\hline Post partum hemorrhage & 0.96 & 0.83 & 1.11 & 0.52 \\
\hline EBL >1000cc & 0.94 & 0.87 & 1.02 & 0.14 \\
\hline Shoulder dystocia outcomes & & & & \\
\hline Shoulder dystocia & 1.01 & 0.86 & 1.19 & 0.93 \\
\hline Number of maneuvers $\geq 3$ & 1.23 & 0.84 & 1.81 & 0.27 \\
\hline Preeclampsia/gestational HTN outcomes & & & & \\
\hline Eclampsia & 1.54 & 0.74 & 3.21 & 0.25 \\
\hline Severe hypertension ${ }^{*}$ & 0.86 & 0.77 & 0.96 & $<0.01$ \\
\hline ICU admission & 0.28 & 0.18 & 0.44 & $<0.01$ \\
\hline Pulmonary edema & 0.95 & 0.57 & 1.58 & 0.84 \\
\hline Creatinine $\geq 2$ mg/dL & 1.18 & 0.71 & 1.97 & 0.53 \\
\hline
\end{tabular}

Any two maternal SBP $\geq 160 \mathrm{mmHg}$ or any two maternal DBP $\geq 110 \mathrm{mmHg}$ 